\title{
Analysis of Acoustic Properties of the Forest in Winter and Spring
}

\author{
Doo-Heon Kyon ${ }^{1}$, Jeong-Hee Lee ${ }^{2}$, Ji-Seon Han $^{1}$ and Myung-Jin Bae ${ }^{1}$ \\ ${ }^{1}$ Electronics Engineering Department, Soongsil University \\ ${ }^{2}$ Korea Forest Research Institute \\ ${ }^{1}$ kdhforce@gmail.com, ${ }^{2}$ jeong86@forest.go.kr, ${ }^{1}$ zi987@naver.com, ${ }^{1}$ mjbae@ssu.ac.kr
}

\begin{abstract}
This research measures the overall acoustic properties of spring and winter, and their difference is investigated from the perspective of environmental change. Forest in winter is very calm with occasional sound of birds and is devoid of insect sounds. The frequency components of winter forests are shifted towards the lower frequencies however, unique sounds caused by walking on snow compensates for this. Spring forests gives off a sense of gradually increasing vitality moving away from the calnof winter. Especially, as both the variety of bird species that cry and the frequency of those cries are increased significantly in the spring, the ratio of middle to high tone energies of the sound was about three times that of the $10 \%$ measured during winter. In all environments volume was louder than winter.
\end{abstract}

Keywords: Winter, Spring, Forest, $A 7 B^{\star}$

\section{Introduction}

As society develops there is great interest in factors that directly and indirectly affect health and well-being. During the 90's in urban societies the main interest was focused on pollutions that directly damage the body, however, these days indirect pollutions such as noise pollution that affect the mind are garnering more awareness[1].

The sounds produced in the city are dependent on the characteristic of that space, for example sounds caused by transportation means such as cars, trains, airplanes, and commercial baildings such as AC noise and even the sounds due to conversation in a busy street. Especially the increase in the number of cars have lead to the expansion of roads and thus their proximity to apartment complexes, hospitals, schools and etc. have also increased leading to more noise con plaints due to traffic noise. Furthermore, noise that is occurred by a major transportation like subway becomes a part of representative sound of the city. Mostly these sounds are classified as noise [2]. On the other hand, the natural sound of forest is known to aid n meditation and spiritual healing. So people listen to recorded natural sound or visit fores [3]. Meditating to the sounds lush forests and waterfalls is a representative image of forest sounds. However, it's difficult to characterize the overall sound of the forest, because the energy, pattern and frequency characteristics of forest sound greatly very due to the season and the environment. The objective of this research is to derive an overall characteristic of forest sounds by taking into account forest sounds of both winter and spring.

\section{Recording and Measurement Environment}

The research team recorded and measured forests sounds in predetermined cases focusing on three locations (Mt.Gwanak, Mt.Odae, and Saneum Recreational Forest). The sounds were recorded in the order of Mt.Gwanak, Saneum Recreational Forest, and Mt.Odae. Four 
representative locations of forests sounds were chosen as shown in the table below and sounds were recorded in two instances, noon and after dark. In addition, recordings were made on typical spring and winter days, meaning when it did not rain or snow. The sounds were analyzed using A7B[4] frequency band energy ratio and the volume area.

Table 1. Four Representative Locations of Forest Sounds

\begin{tabular}{cr}
\hline Type & Environmental Characteristics \\
\hline $\begin{array}{c}\text { Summit } \\
\text { Forest } \\
\text { Stream }\end{array}$ & $\begin{array}{r}\text { Relatively windy area with less trees and with large rocks } \\
\text { A typical woody area with lots of trees } \\
\text { Waterfall }\end{array}$ \\
$\begin{array}{r}\text { Valley region of the forests where streams can be heard } \\
\text { An environment where the free fall of the water differentiates itself } \\
\text { from the sounds of streams }\end{array}$ \\
2.1. Mt. Gwanak
\end{tabular}

There are many bent trees, and low moisture content $m$ the dirt in the forest area. The forest entrance has a slight slope, which tends to increase rapidly according to the route taken. There are equal amounts of hardwoods and softwoods with various flowering plants. There are large numbers of visitors and many forks in the routes. The summit has a lot of large rocks more than forest zone. University and downtow buildings can be seen, with helicopters and planes flying overhead oftên

The waterfall is a two-step structure, with the upperfloor being $3 \mathrm{~m}$ and the lower floor being $4 \mathrm{~m}$. The ground is composed of natural gramite. The water flows straight with little difference in current due to the flow as the width of the channel is large. The stream area has a high ratio of granite which is strong against erosion. From midstream to downstream the slope decreases and the downstream is in close proximity to the trail and the stream. A stream was resored after it was blocked due to a land slide, with lot human presence by the stream and the bridge.

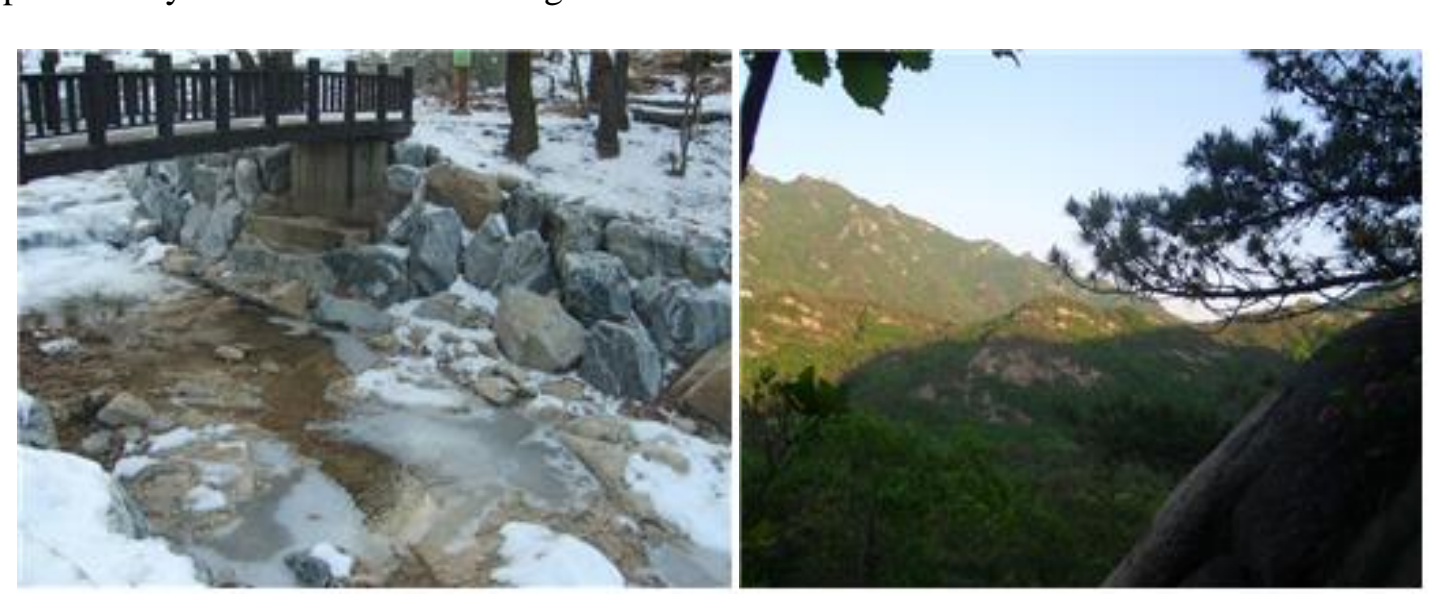

Figure 1. Winter and Spring Environment of Mt.Gwavnak

\subsection{Mt. Odae}

There is little human presence in Mt.Odae with large amount of fallen leaves. The sounds were recorded in locations with steep slopes, the trees are tall with various plant. The large of 
number of trees and foliage block the sunlight and there is a sense of humidity. The adjacent mountain peak is easily visible from the summit area. Trees surrounding the area are mostly red pine trees. Because a large stream is running immediately below the area, the sound of water has a continuous effect.

The Guryong waterfall is selected as a recording location that is about $15 \mathrm{~m}$ high. There is a deep lake at the bottom of the waterfall which serves as the source of water for the streams in the mountain. There are large rocks surrounding the waterfall, and there are warning signs alongside life belts and life vests. Water from the rock cliff makes a deep pool of the stream area. Compare with the others, stream of Mt.Odae has the greatest water and the fastest currents. The area is composed of large rocks and there are steel bridges for visitors.
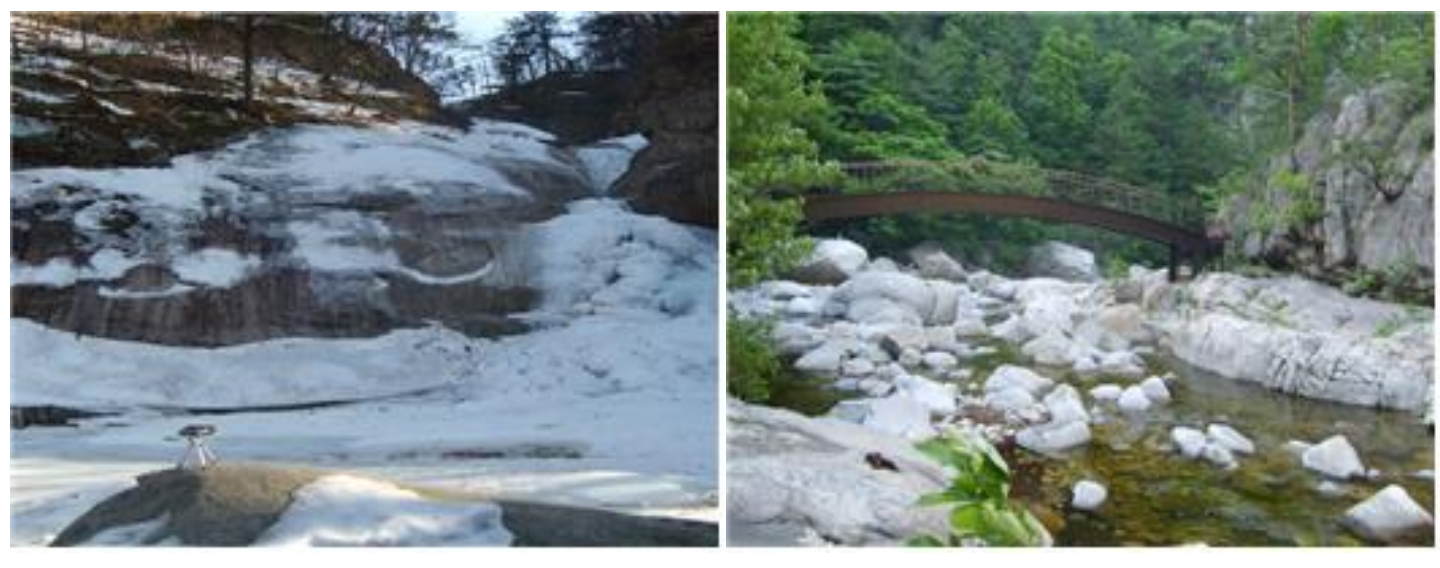

Figure 2. Winter and Spring Environment of Mt.Odae

\subsection{Saneum Recreational Park}

The forest area of the S neym recreattonal park located in Yang Pyung, has a slight slope with various types of trees growing densely. In general, the trees are tall. In the summit area is a hill with little to no visitors with old allen leaves piled deeply with a stream flowing in the distance. There are too many trees between the stream and the summit area for it to be heard.

The waterall is very low The surrounding area is densely packed with trees and foliage blocking the sunlight, with a 10 moss growing due to the humidity. The water source is the SeokSan Valley, with aslight slope and shallow water. The streambed is filled with pebbles and eroded rocks.
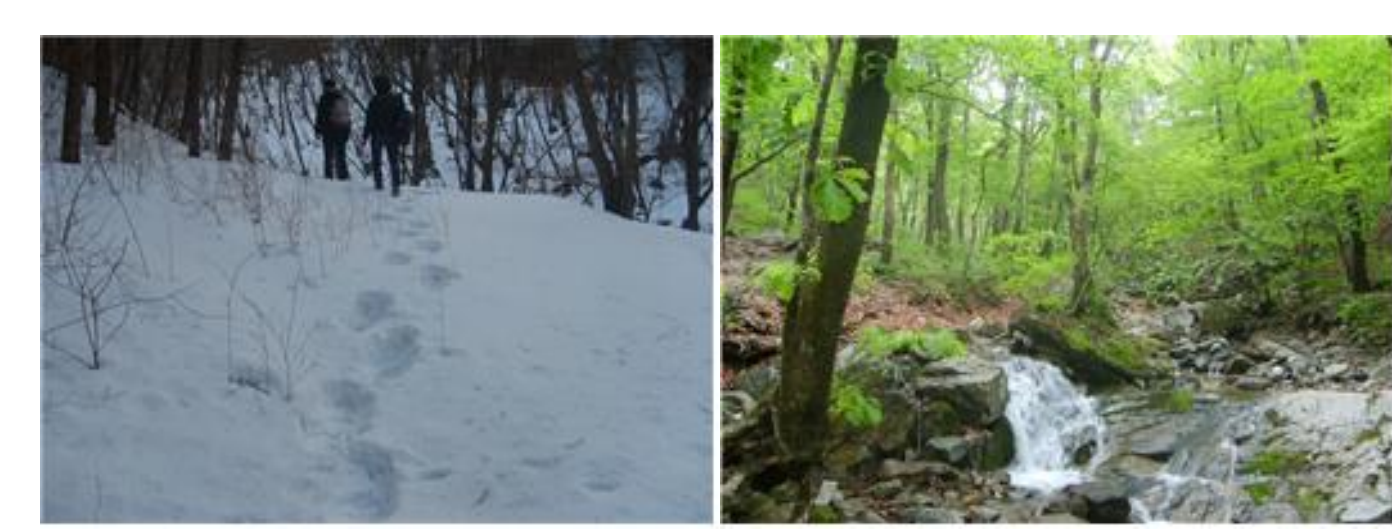

Figure 3. Winter and Spring Environment of Saneum Recreational Forest 


\section{Result}

Because effect of forest is very broadly, it is analyzed by fundamental sound element for deriving an overall characteristic. The recording made during noon was used. Volume was analyzed based on the average values. The sound was analyzed focusing on the frequency and volume characteristics, and every measurement was made using the following guideline in order to generalize the result.

Not raining or snowing

No excessive wind

Exclude all manmade sounds

Exclude birds and insects crying in close proximity Prevents acoustic characteristic from becoming extreme.

For waterfalls and streams the measurements were made when they were audible

Values are rounded at the decimal place thus the sum of the percentile is $100 \pm 1$ '

\subsection{Winter}

In the summit and forest areas the 55 70\% of the sound energies were focused in the lowlow to the mid-low frequencies. However, since the volume is small at approximately $32 \sim 36 \mathrm{~dB}(\mathrm{~A})$ there is little effect in the auditory experience. The summit area was affected by wind the most, causing the greatest difference between the minimum and maximum volumes at $7 \mathrm{~dB}[5]$.

Forest area had an approximate yolume of $32 \mathrm{~dB}(\mathrm{~A})$ quietest amongst the measured areas. This is due to the minimum effect or wind, and due to the fact that there are no leaves rustling or the birds or insects being winter.

The stream and waterfallarea had the higher sound energy ratios than summit and forest area. The difference between the stream and the waterfall was energy ratios of the Ultra-Low and low frequencies. Waterfall is measured energy ratios of the ultra-high and high frequencies more than two-times than stream influenced of impulse sound component. When water drops fall from top to bottom.

Other frequencies showed similar pattern. Generally, the volume of the stream and waterfall areas were about $48 \mathrm{~dB}(\mathrm{~A})$. The difference in volume of streams and waterfalls are too dependent on the logation of measurement which makes such differences insignificant.

\section{Table 2. A7B Energy Ratio of a Winter Forest}

\begin{tabular}{cccccccc}
\hline Area & Ultra-Low & Low & Mid-Low & Mid & Mid-High & High & Ultra-High \\
\hline Forest & 24 & 24 & 22 & 21 & 6 & 3 & 1 \\
Summit & 12 & 23 & 21 & 27 & 12 & 4 & 1 \\
Waterfall & 3 & 3 & 8 & 22 & 39 & 20 & 6 \\
Stream & 2 & 3 & 19 & 38 & 27 & 9 & 1 \\
\hline Average & 10 & 13 & 17 & 27 & 21 & 9 & 2 \\
\hline
\end{tabular}




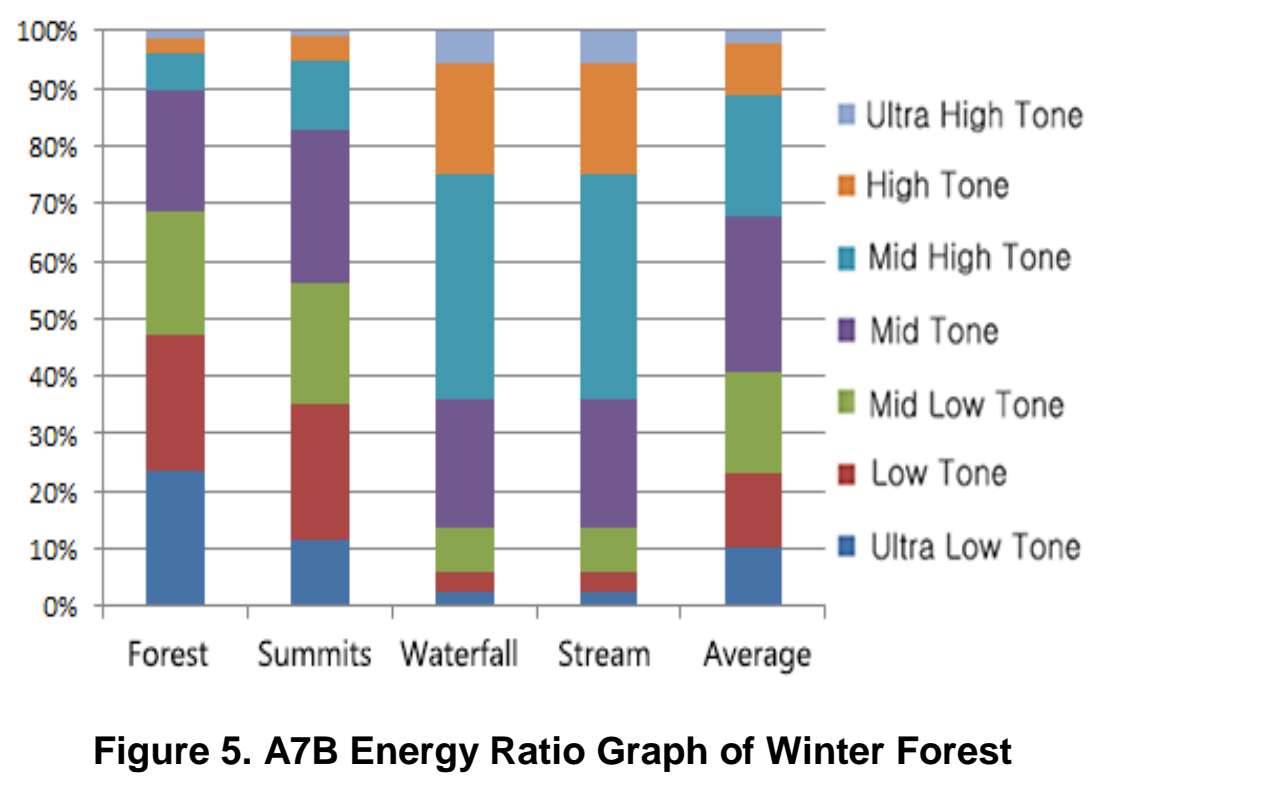

Table 3. Volume Characteristics of Winter(dB(A): Slow)

\begin{tabular}{|c|c|c|c|c|c|c|c|}
\hline \multirow{2}{*}{ Environment } & \multirow{2}{*}{ Region } & & oon & 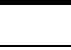 & \multicolumn{3}{|c|}{ After Dark } \\
\hline & & Min & Avg & $\operatorname{Max}$ & Min & Avg. & $\operatorname{Max}$ \\
\hline \multirow{4}{*}{ Forest } & Gwanak & & 31 & 32 & 31 & 32 & 34 \\
\hline & Saneum & & 32 & 33 & 31 & 31 & 32 \\
\hline & & 32 & & 33 & 32 & 32 & 32 \\
\hline & Avg. & 31 & 32 & 33 & 31 & 32 & 33 \\
\hline \multirow{4}{*}{ Summit } & Gwanak & & 37 & 44 & 34 & 39 & 45 \\
\hline & & & 33 & 37 & 39 & 36 & 35 \\
\hline & & 37 & 39 & 42 & 40 & 42 & 44 \\
\hline & & 3. & 36 & 41 & 38 & 39 & 41 \\
\hline \multirow{4}{*}{ Water } & & 44 & 45 & 45 & 44 & 44 & 45 \\
\hline & apr. & 52 & 55 & 59 & 51 & 54 & 57 \\
\hline & & 44 & 44 & 44 & 43 & 43 & 44 \\
\hline & & 47 & 48 & 49 & 46 & 47 & 49 \\
\hline \multirow{4}{*}{ Stream } & & 46 & 47 & 47 & 46 & 47 & 47 \\
\hline & & 49 & 52 & 55 & 48 & 48 & 49 \\
\hline & Odae & 48 & 48 & 48 & 46 & 46 & 47 \\
\hline & Avg. & 48 & 49 & 50 & 47 & 47 & 48 \\
\hline \multicolumn{2}{|c|}{ Overall average } & 40 & 41 & 43 & 40 & 41 & 43 \\
\hline
\end{tabular}

\subsection{Spring}

Waterfall areas had the highest ratio of ultra-low tone components out of all areas. While the water fall from a high ground to a low ground, ultra-high tone is occurred by droplets bumped and bounced.

The acoustic properties of a waterfall is dependent on its size and shape for example, the Niagara falls which has large volumes of water falling without resistance, the low-low to midlo frequencies are increased whereas the high to high-high frequencies are decreased[5]. Compared to winter, both the waterfall and the stream areas had slightly decreased low-low to mid-low tone components with a slightly increased high frequency component. These slight 
changes are due to the ice on the surface which changes the mount of waters splashing. The volume was most effected by the ice formation with winter having a volume $12 \mathrm{~dB}$ higher than spring.

The forest area also had a significant change compared to that of winter. Because the winter forest sounds are lacking in components such as bird calls or leaves rustling, energy is rare in mid-high tone. However, during the spring and bird call, energy in mid-high tone is over three times. Summit areas show similar acoustic characteristics compared to a dense forests. However, due to less number of birds, it seems that energy in high tone decreased and increased energy in low tone as reaction.

Taking into account the analysis results, the factors which affect the forests sounds with the changes of seasons is the formation of ice and the activity level of life. There is difference in forest sound between winter and spring, because the formation ice changed the activity level of life. The below figure is a portion of a spectrogram of the Mt.Gwanak's forest area during the winter and spring. Unlike winter forest sounds, spring forest-sounds have noticeable bird sounds in the $1000 \sim 10000 \mathrm{~Hz}$ region. There were on average 5 types of birds that were observed, being measured on average 8 times per minute. There was lype of insect sound that was observed during the night, being measured on average 2 times per minute.

Table 4. A7B Energy Ratio of a Spring Forest

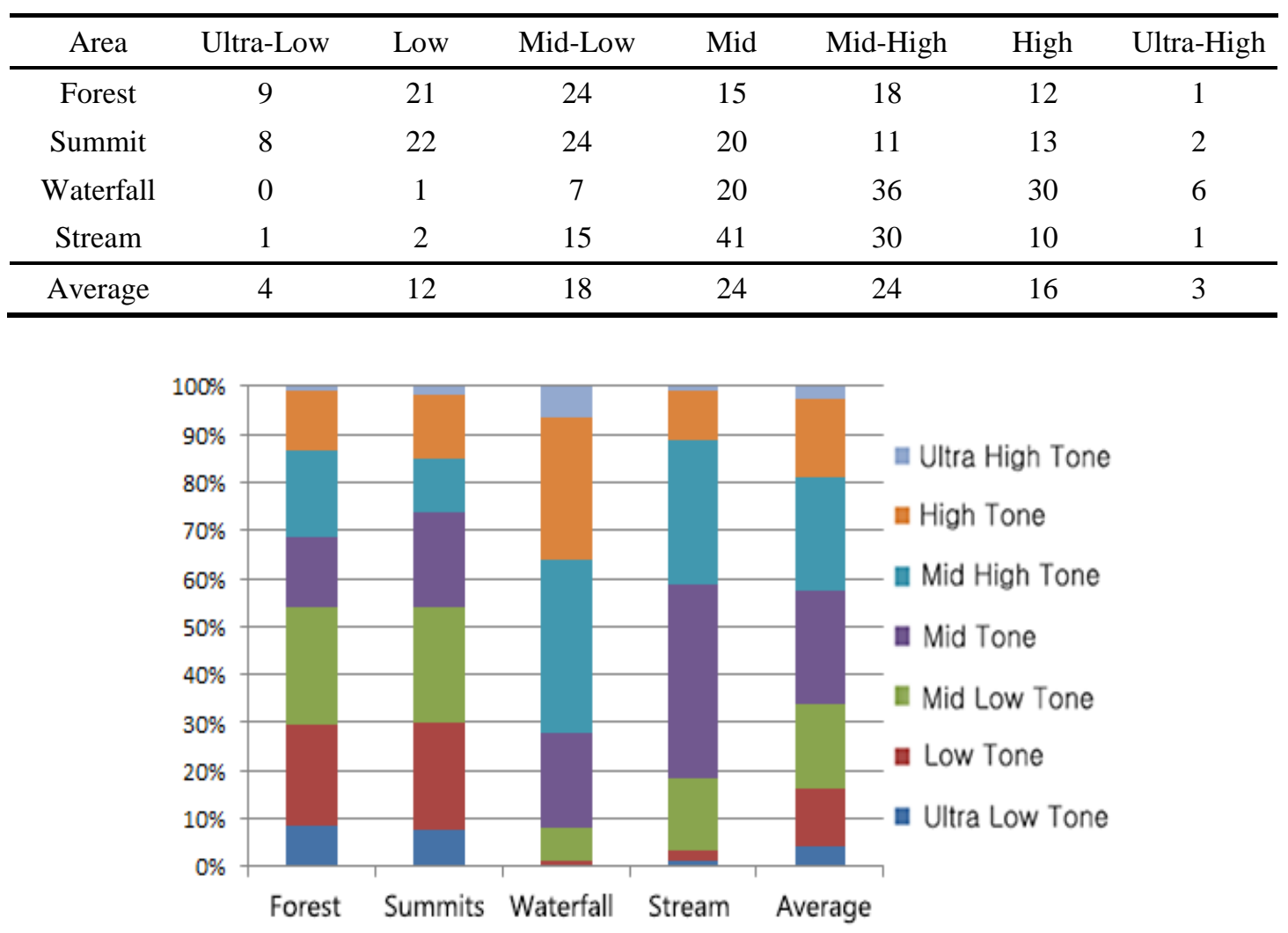

Figure 6. A7B Energy Ratio Graph of Spring Forest 
Table 5. Volume Characteristics of Spring (dB(A): Slow)

\begin{tabular}{|c|c|c|c|c|c|c|c|}
\hline \multirow{2}{*}{ Environment } & \multirow{2}{*}{ Region } & \multicolumn{3}{|c|}{ Noon } & \multicolumn{3}{|c|}{ After Dark } \\
\hline & & Min & Avg. & $\operatorname{Max}$ & Min & Avg. & Max \\
\hline \multirow{4}{*}{ Forest } & Gwanak & 34 & 36 & 43 & 35 & 36 & 38 \\
\hline & Saneum & 38 & 39 & 40 & 38 & 38 & 38 \\
\hline & Odae & 40 & 41 & 41 & 39 & 40 & 41 \\
\hline & Avg. & 37 & 39 & 41 & 37 & 38 & 39 \\
\hline \multirow{4}{*}{ Summit } & Gwanak & 35 & 36 & 40 & 38 & 38 & 40 \\
\hline & Saneum & 39 & 40 & 41 & 39 & 39 & 40 \\
\hline & Odae & 40 & 43 & 45 & 40 & 42 & 43 \\
\hline & Avg. & 38 & 40 & 42 & 39 & 40 & 41 \\
\hline \multirow{4}{*}{ Water } & Gwanak & 51 & 52 & 53 & 50 & 50 & 51 \\
\hline & Saneum & 65 & 65 & 66 & 65 & 0 & 65 \\
\hline & Odae & 63 & 64 & 64 & 63 & & 64 \\
\hline & Avg. & 60 & 60 & 61 & 59 & 60 & 60 \\
\hline \multirow{4}{*}{ Stream } & Gwanak & 50 & 50 & & 50 & 50 & 51 \\
\hline & Saneum & 63 & 63 & & & & 63 \\
\hline & Odae & 53 & 54 & & & 53 & 54 \\
\hline & Avg. & 55 & 56 & 57 & 55 & 55 & 56 \\
\hline \multicolumn{2}{|c|}{ Overall average } & 48 & 49 & 50 & 48 & 48 & 49 \\
\hline
\end{tabular}

Not only is the change in season fromwinter to spring visually different but the sound characteristics showed a large change And the overall acoustic characteristics were analyzed focusing on the A7B and the volume change The winter sounds are quiet and calm. The sounds of stepping through snow compensating it. While the springs sounds are full of life with the melting ice and increase in bird calls. This result may be used in explaining the specific acoustic characteristics of forest sounds, in the future, the forest sounds of summer and autumn will be analyzed to attain a forest sounds characteristics per season and environment.

\section{Acknowledgements}

This article is a revped and expanded version of a paper entitled "Analysis of Forest Acoustics in Winter and Spring" presented at International Symposium on Advanced and Applied Convergence held on November 14-16, 2013 at Seoul, Korea.

\section{Reference}

[1] D. N. Bengston and T. J. Webb, "Shifting Forest Value Orientations in the United States", Environmental values, vol. 13, no. 3, (2004), pp. 373-392.

[2] D. H. Kyon and M. J. Bae, "Analysis of Acoustic Psychology of City Traffic and Nature Sounds", Journal of the Acoustical Society of Korea, vol. 28, no. 4, (2009), pp. 356-362.

[3] W. S. Shin, P. S. Yeoun and J. H. Lee, "The Impact that a Forest Experience Influences on a Human Mental State Stability", vol. 11, no. 3, (2007), pp. 37-43.

[4] D. H. Kyon, M. S. Kim and M. J. Bae, "The Standardization of Partitioning Audible Sound by A7B, Communications in Computer and Information Science", vol. 351, (2012), pp. 271-277.

[5] D. H. Kyon, J. H. Lee and M. J. Bae, "Analysis of Forest Acoustics in Winter and Spring", ICACT2013 AACL, vol. 1, (2013), pp. 49-51. 


\section{Authors}

\section{Doo-Heon Kyon}

$\mathrm{Ph} . \mathrm{D}$. in Engineering, Senior Researcher,

Sori Sound Engineering Research Institute, Soongsil University.

\section{Jeong-Hee Lee}

Div, Forest Recreation \& Culture, Researcher, Korea Forest Research Institute.

\section{Ji-Seon Han}

Master Course in Engineering, Senior Researcher Assistant, Sori Sound Engineering Research Institute, Soongsil University

\section{Myung-Jin Bae}

Ph.D. in Engineering, Professor,

School of Electronics Engineering, Soongsil University.

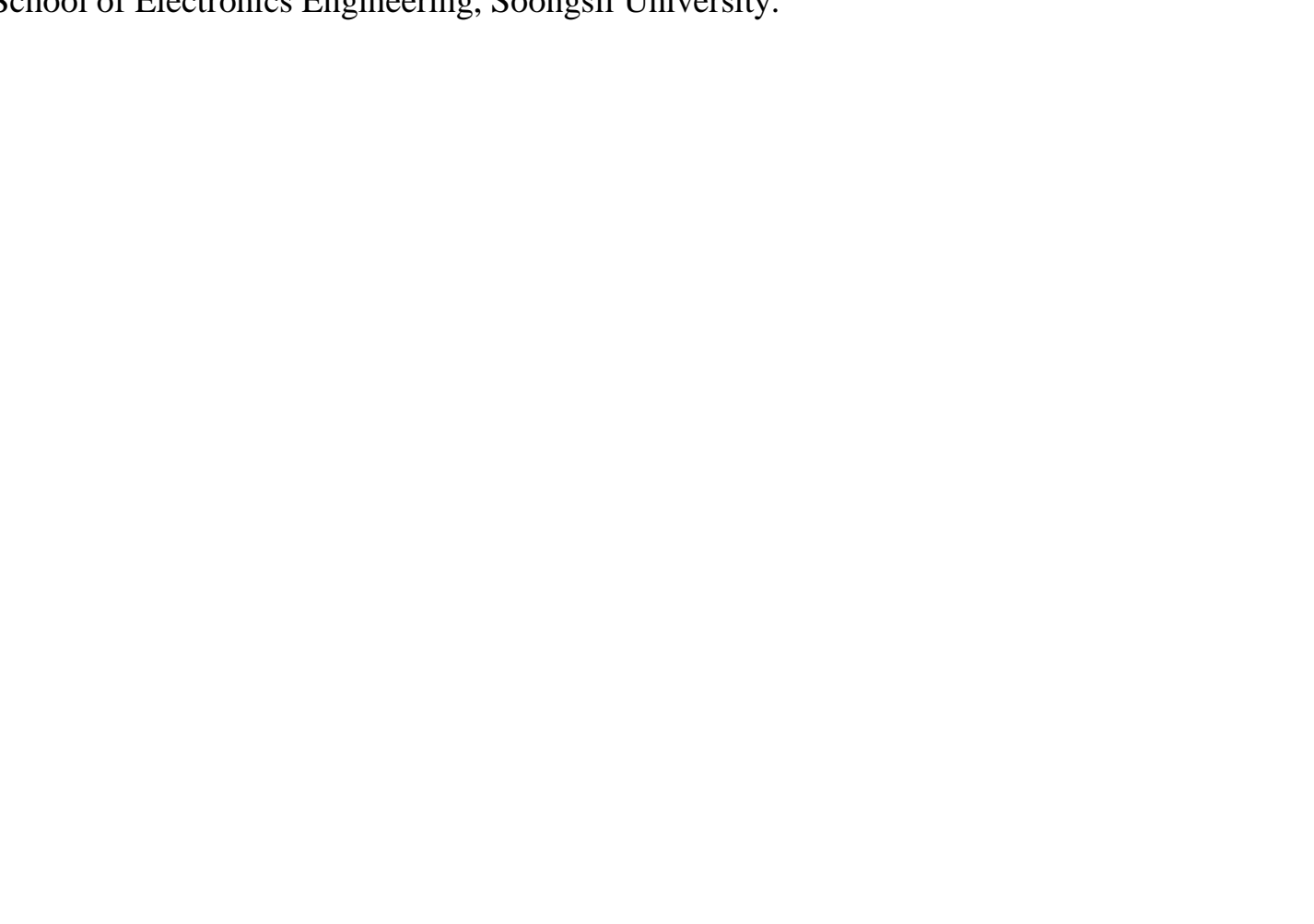

